\title{
FLT3 mutations in canine acute lymphocytic leukemia
}

Steven E Suter ${ }^{1,2,3}$, George W Small ${ }^{3,5}$, Eric L Seiser ${ }^{4}$, Rachael Thomas ${ }^{2,4}$, Matthew Breen ${ }^{2,3,4}$, Kristy L Richards ${ }^{2,3,5^{*}}$

\begin{abstract}
Background: FMS-like tyrosine kinase 3 (FLT3) is a commonly mutated protein in a variety of human acute leukemias. Mutations leading to constitutively active FLT3, including internal tandem duplications of the juxtamembrane domain (ITD), result in continuous cellular proliferation, resistance to apoptotic cell death, and a poorer prognosis. A better understanding of the molecular consequences of FLT3 activation would allow improved therapeutic strategies in these patients. Canine lymphoproliferative diseases, including lymphoma and acute leukemias, share evolutionarily conserved chromosomal aberrations and exhibit conserved mutations within key oncogenes when compared to their human counterparts. A small percentage of canine acute lymphocytic leukemias (ALL) also exhibit FLT3 ITD mutations.
\end{abstract}

Methods: We molecularly characterized FLT3 mutations in two dogs and one cell line, by DNA sequencing, gene expression analysis via quantitative real-time PCR, and sensitivity to the FLT3 inhibitor lestaurtinib via in vitro proliferation assays. FLT 3 and downstream mediators of FLT3 activation were assessed by Western blotting.

Results: The canine B-cell leukemia cell line, GL-1, and neoplastic cells from 2/7 dogs diagnosed cytologically with ALL were found to have FLT3 ITD mutations and FLT3 mRNA up-regulation. Lestaurtinib, a small molecule FLT3 inhibitor, significantly inhibited the growth of GL-1 cells, while not affecting the growth of two other canine lymphoid cell lines without the FLT3 mutation. Finally, western blots were used to confirm the conserved downstream mediators of FLT3 activating mutations.

Conclusions: These results show that ALL and FLT3 biology is conserved between canine and human patients, supporting the notion that canine ALL, in conjunction with the GL-1 cell line, will be useful in the development of a relevant large animal model to aid in the study of human FLT3 mutant leukemias.

\section{Background}

FMS-like tyrosine kinase 3 (FLT3), one of the most commonly mutated genes in human leukemias, is a class III receptor tyrosine kinase that is an important regulatory gene involved in normal hematopoiesis $[1,2]$. FLT3 is expressed predominantly on myeloid and lymphoid hematopoietic progenitors, where the receptor, once bound by its cognate ligand (FLT3 ligand, FL), activates a variety of downstream targets. These include proteins in the signal transducers and activators of transcription (STAT), mitogen-activated protein (MAP) kinase, and AKT pathways that are all involved in regulating proliferation, differentiation, and cell survival $[1,2]$. In vitro

\footnotetext{
* Correspondence: kristy_richards@med.unc.edu

${ }^{2}$ Center for Comparative Medicine and Translational Research, North Carolina State University, Raleigh, NC, USA

Full list of author information is available at the end of the article
}

studies have shown that constitutively activated FLT3 triggers downstream signaling pathways resulting in continuous cellular proliferation and resistance to apoptotic cell death. Constitutively activated FLT3 occurs via two main mechanisms: coexpression of FL, which leads to activation via autocrine, paracrine, or intracrine signaling, or via mutation of the FLT3 gene itself, conferring ligand independence [3-7]. Such mutations are internal tandem duplications of the juxtamembrane domain (ITD), point mutations of the juxtamembrane domain, or point mutations of the second tyrosine kinase domain (TKD). In transgenic murine model systems, constitutively activated FLT3 contributes to the leukemic phenotype $[1,2,8,9]$.

The majority of human acute leukemias, including $100 \%$ of B-cell lineage acute lymphoblastic leukemias (ALL), 27\% of T-lineage ALL, and 89\% of acute

\section{Ciomed Central}


myelogenous leukemias (AML) overexpress FLT3 $[10,11]$. ITD mutations are found in $3 \%$ of patients with myelodysplastic syndromes (MDS) [1,12], and up to $15 \%$ and $25 \%$ of pediatric and adult AML patients, respectively $[1,2,13-15]$. In both pediatric and adult AML patients, the presence of an ITD mutation is associated with a significantly higher relapse rate and worse overall survival [13-15]. FLT3 ITD mutations rarely occur in adult acute lymphoblastic leukemias (ALL) of B-cell origin and childhood ALL [1,2]. Interestingly, some of the highest levels of FLT3 expression occur in infant and childhood ALL, therefore, a mechanism other than mutation constitutively activates FLT3 in these cases [16]. As a therapeutic target, FLT3 is appealing since it is up-regulated in a significant number of acute leukemias and its protein expression is restricted to primitive and immature hematopoietic progenitors. Modest results from clinical trials with a variety of smallmolecule FLT3 inhibitors suggest that improved understanding of FLT3 mutations and the resultant aberrations in signaling may be needed before we realize the full therapeutic potential of these agents.

The domestic dog (Canis familiaris) is a useful largeanimal model of naturally occurring cancers, including hematologic malignancies such as lymphomas and leukemias. Canine hematologic malignancies share extensive similarities with their human counterparts with regards to clinical presentation, tumor biology and response to therapy $[17,18]$ and, in addition, human and canine hematologic malignancies share evolutionarily conserved chromosomal aberrations as well as conserved mutations within key oncogenes $[19,20]$. Therefore, canine hematologic malignancies are recognized as appropriate models of their human counterparts [17], and comparative studies between human and canine patients may reveal common mechanisms of oncogenesis relevant to both species [21].

Recently, FLT3 mutations were reported in 4/57 (7\%) of dogs with cytologically and immunophenotypically confirmed ALL [19], suggesting that this important mechanism of leukemia development and/or progression might be another instance of cross-species conservation of pathogenic mechanism. Three dogs with B-cell ALL harbored FLT3 ITD mutations of exons 14/15, while one dog with ALL of an unknown phenotype had a TKD-PM in exon 20. The functional consequences of the identified mutations (i.e. FLT3 up-regulation) were not examined.

Another suggestion of cross-species conservation of FLT3 activation came from our efforts to further characterize five previously reported malignant canine lymphoid cell lines- GL-1, CL-1, 17-71, CLGL-90, and CLL-1390 (manuscript submitted, Seiser EL, Thomas R, Richards KL, Byler KK, Breen T, Moore P, Suter SE,
Breen M. Reading Between the Lines: Genomic Characterization of Five Widely Utilized Canine Lymphoid Tumor Cell Lines). Using array comparative genomic hybridization $(\mathrm{aCGH})$ analysis, we found that GL-1 [22], a B-cell leukemia cell line, has an extensive copy number increase of the proximal half of dog chromosome 25, which harbors the FLT3 locus. Subsequent FISH analysis using a BAC clone containing the entire FLT3 sequence, showed a copy number increase to $4 \mathrm{~N}$ on chromosome 25. These initial data suggested that the GL-1 cell line could be a relevant in vitro model for FLT3 activation, and if so, that canine leukemia models could be of use in the development of targeted FLT3 inhibitors.

The aim of this study was to determine if the canine GL-1 cell line and samples obtained from dogs diagnosed with ALL contain FLT3 mutations, to compare any identified mutations to those previously reported in both canine and human leukemia patients, and to determine whether the functional consequences of FLT3 mutation are conserved between dogs and humans.

\section{Methods}

\section{Cell lines}

The canine lymphoid cell lines, GL-1 (B-cell leukemia) [22], 17-71 (B-cell lymphoma) [23], and CLGL-90 (chronic large granular $\mathrm{T}$ cell leukemia, kind gift from Dr. Maxie Wellman, Ohio State University) [24], and human cell line, MV4-11 (biphenotypic myelomonocytic cell line) [25], were maintained in RPMI 1640 culture medium (Mediatech, Inc., Hendon, VA) supplemented with $10 \%$ fetal bovine serum (FBS, Mediatech, Inc), $2 \mathrm{mM}$ L-glutamine (Mediatech, Inc) and $100 \mathrm{mg} / \mathrm{ml}$ Primocin (Invivogen, San Diego, CA) at $38^{\circ} \mathrm{C} / 5 \% \mathrm{CO}_{2}$. All cell lines tested negative for mycoplasma infection using a PCR-based test kit (AppliChem, Cheshire, CT). The GL-1 and CLGL-90 cell lines exhibit near normal ploidy $(2 n=78$ for the domestic dog), with a range of $75-77$ chromosomes and 77-82 chromosomes, respectively. The 17-71 cell line is hyperploid, with a range of 102-108 chromosomes. These cell lines were verified to match available published karyotypic and immunophenotyping information (manuscript submitted, Seiser EL, et al.).

\section{Sample recruitment}

Three ml ethylenediaminetetraacetic acid (EDTA) blood samples were obtained during routine staging after owner consent via venipuncture from seven dogs presenting to the North Carolina State College of Veterinary Medicine Veterinary Teaching Hospital (NCSUVTH) with clinical signs and hematologic abnormalities consistent with acute lymphoblastic leukemia. The study protocol was approved by the Institutional Animal Care and Use Committee of North Carolina State University. 
Blood smears stained with May Grunwald Giemsa were examined by a board-certified veterinary clinical pathologist. Morphological evaluation included a 200-cell differential white blood cell count. Flow cytometry was performed (Clinical Immunology Service, NCSU-VTH) using a panel of antibodies against CD3, CD4, CD8, CD21, CD45, CD34, CD14, and CD79a. A diagnosis of ALL was made based on a combination of morphological evaluation of blood and/or bone marrow smears, immunophenotyping, and hemogram analysis. These criteria included $>30 \%$ blasts in the peripheral blood or bone marrow, concurrent cytopenias, negative staining of the neoplastic cells using a myeloid marker (CD14), and positive staining using CD34, CD79a, CD21 (B-cell ALL), or CD34, CD3, CD4, and CD8 (T-cell ALL). ALL was differentiated from chronic lymphoid leukemia (CLL) and the leukemic phase of lymphoma on the basis of cell morphology, CD34 expression, and the distribution of organ involvement.

The canine ALL patients included two 8-year old and one 9-year old male castrated Labrador Retrievers, one 6-year old female spayed Schipperke, one 10-year old male castrated Border Collie, one 10.5-year old female spayed Doberman Pinscher, and one 8-year old male castrated mixed-breed dog. The ALL phenotypes were: three B-cell ALL, three ALL of unknown phenotype, and one dual-positive (i.e. T and B-cell markers) ALL. Five of these patients had $\geq 100,000 / \mathrm{ml}$ leukemic blasts in the peripheral blood (including both dogs harboring the FLT3 ITD), while three patients had $<30,000 / \mathrm{ml}$ leukemic blasts.

\section{Polymerase chain reaction (PCR)}

Genomic DNA was prepared from whole blood collected by venipuncture from dogs diagnosed cytologically with ALL or from aliquots of cultured cell lines using the ZR Genomic DNA II kit (Zymo Research, Orange, CA) according to manufacturer instructions. PCR was conducted in $50 \mathrm{ul}$ reactions containing $1 \mathrm{ul}$ of genomic DNA ( $35 \mathrm{ng}) ; 25$ ul Taq PCR MasterMix (Qiagen Inc., Valencia, CA), and $400 \mathrm{nM}$ each of forward and reverse primers designed within intronic regions of the FLT3 gene and prepared by the Nucleic Acids Core Facility (University of North Carolina, Chapel Hill, NC). The FLT3 14/15 intronic primer pairs, 5'CCA TTT CTG AGG GAC TGC-3' and 5'-GCC TTG AAA CAT GGC AAG C-3', were used for amplification of the exon regions 14 through 15 corresponding to the juxtamembrane domain [19]. The FLT3 20 intronic primer pairs, 5'-TCA CCT GGA ATT CCT ACT GAA C3' and 5'-TGT ACT ACA GCG GTT GTG GAC-3' were used for amplification of exon 20 corresponding to the tyrosine kinase domain [19]. PCR reaction conditions were: $95^{\circ} \mathrm{C}$ for $3 \mathrm{~min}$; followed by 37 cycles of $94^{\circ} \mathrm{C}$ for $30 \mathrm{~s} ; 52^{\circ} \mathrm{C}(\mathrm{FLT} 314 / 15)$ or $55^{\circ} \mathrm{C}$ (FLT3 20) for $30 \mathrm{~s}$; and $72^{\circ} \mathrm{C}$ for $1 \mathrm{~min}$ with a final elongation step of $72^{\circ} \mathrm{C}$ for $10 \mathrm{~min}$. PCR amplicons were separated through a $1.5 \%$ agarose gel, followed by ethidium bromide staining and visualization under ultraviolet light. DNA was extracted from bands excised from the gel using a QIAquick Gel Extraction kit (Qiagen). Purified DNA was then sequenced using the previously mentioned PCR primers (Genomic Analysis Core Facility, University of North Carolina, Chapel Hill, NC).

\section{RNA preparation and quantitative real-time PCR}

Peripheral blood mononuclear cells from a normal dog were isolated as previously described [26], then frozen in Trizol (Invitrogen, Carlsbad, CA) until RNA extraction per manufacturer's instructions. ALL case 1 had an excisional lymph node biopsy that was immediately stored in Trizol at $-80^{\circ} \mathrm{C}$ until extraction. Cell line pellets were resuspended and frozen in Trizol at $-80^{\circ} \mathrm{C}$ until extraction. RNA from other ALL cases was obtained from $200 \mathrm{ul}$ of peripheral blood added to $1 \mathrm{ml}$ RNAlater (Qiagen), then frozen at $-20^{\circ} \mathrm{C}$ until Trizol extraction.

Total RNA from each sample was used to generate cDNA for downstream analysis (Quantitect Reverse Transcription Kit, Qiagen). Quantitative real-time PCR (qRT-PCR) was performed using the Quantitect SYBR Green Kit (Qiagen) and an iCycler (BioRad, Hercules, CA). The gene RPL32 was selected as the reference for quantitative analysis based on its stable expression across all samples examined by gene expression microarray (see below); PCR primers (forward: 5'-ATG CCC AAC ATT GGT TAT GG-3', reverse: 5'-CTC TTT CCA CGA TGG CTT TG-3') were designed as described previously [27]. FLT3 primers (Entrez GeneID: 486025, forward: 5'-CAG AGG CAG TGT ATG GAG CA-3', reverse: 5'-GGC AAT TCA GGG AAC TGT GT-3') were designed using NCBI Primer-BLAST (http://blast.ncbi.nlm.nih.gov/Blast. cgi). The reaction efficiency for the primer sets used was calculated using serial dilutions of cDNA, with efficiencies ranging from $90 \%-100 \%$. Relative quantification was performed as described previously [28]. All qRT-PCR assays were performed in triplicate.

\section{Proliferation assays}

Cells were seeded at $4 \times 10^{4}$ cells in a 96-well plate in a total volume of $200 \mathrm{ul}$ and treated with 5 or $10 \mathrm{nM}$ lestaurtinib for 96 hours. Proliferation was measured using Alamar Blue (AbD Serotec Ltd, Oxford, UK) according to manufacturer instructions. Fluorescence was measured using a DTX880 Multimode Detector (Beckman Coulter, Brea, CA) with excitation at $535 \mathrm{~nm}$ and emission at $595 \mathrm{~nm}$. All assays were performed in triplicate and growth experiments were each repeated three times; 
standard error of the mean was calculated for the averages. Proliferation was expressed relative to untreated controls.

\section{Western blotting}

Cells were seeded at $2 \times 10^{6}$ cells in $2 \mathrm{ml}$ of RPMI supplemented with penicillin $\mathrm{G}$ sodium $(100 \mathrm{U} / \mathrm{ml})$, streptomycin sulfate $(100 \mathrm{ug} / \mathrm{ml})$, and $0.5 \%$ bovine serum albumin under serum-free conditions for 24 hours and then treated for 2 hours with or without $10 \mathrm{nM}$ lestaurtinib (LC Laboratories, Woburn, MA). Cells were then lysed in RIPA buffer (Dulbecco's PBS, 0.1\% Sodium Dodecyl Sulfate, $0.5 \%$ Sodium Deoxycholate, and 1\% Ipegal NP-40 supplemented with 1 mM PMSF (phenylmethylsulfonylfluoride), 1x complete protease inhibitor cocktail (Roche Diagnostics, Indianapolis, IN), and $1 \mathrm{x}$ Phosphatase Inhibitor Cocktail 2 (Sigma, St. Louis, MO)). An aliquot was used for protein quantification using the BCA protein assay kit (Pierce Technology, Inc., St. Louis, $\mathrm{MO})$. The remaining sample was mixed with 0.5 volumes of $3 x$ SDS sample buffer ( $1 \mathrm{x}$ equals $31.25 \mathrm{mM}$ Tris- $\mathrm{HCl}$ (pH 6.8), 2\% SDS, 5\% 2-mercaptoethanol, 10\% sucrose, and $0.005 \%$ bromophenol blue). Equivalent protein amounts were run on SDS-PAGE in Tris/glycine/SDS buffer using $10 \%$ acrylamide gels. Resolved proteins were then transferred to a PVDF (polyvinylidene difluoride) membrane Antibodies directed against FLT3, phosphoFLT3, phospho-MAPK (Thr202/Tyr204) and phosphoStat5 (Tyr694) (Cell Signaling, Boston, MA) were used. Anti-beta-actin (Sigma) was used as a loading control. Horseradish peroxidase-conjugated secondary antibodies were used with an ECL or ECL Plus detection reagent (GE Healthcare Bio-Sciences Corp., Piscataway, NJ) to visualize immunoreactive bands.

\section{Results}

Identification of FLT3 ITD mutations in a canine ALL cell line and in canine leukemia patient samples

We first evaluated the canine lymphoid cell lines for the presence of either exon 14/15 ITDs or exon 20 TKD point mutations using genomic PCR. Using previously published primers, the wild-type exon $14 / 15$ product seen in the 17-71 and CLGL-90 cell lines is $500 \mathrm{bp}$ (Figure 1, lanes 3, 4). In contrast, the GL-1 leukemia cell line yielded only a $\sim 525$ bp amplicon (Figure 1 lane 7 ), suggesting the possibility of an ITD and indicative of a complete loss of the wild-type FLT3 sequence. GL-1 cells, therefore, reveal loss of heterozygosity in the area of chromosome 25 containing the FLT3 gene (25 q $\mathrm{LOH})$. No point mutations were identified by DNA sequencing of both exon 14/15 and exon 20 in any of the canine cell lines.

We next examined DNA isolated from seven dogs diagnosed with ALL. A wild-type 500 bp amplicon was

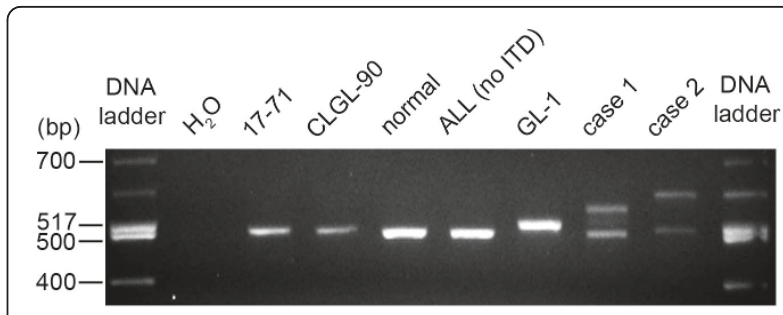

Figure 1 FLT3 PCR of genomic DNA. FLT3 PCR with intronic primers bracketing exons 14 and 15 was performed and the products separated on an agarose gel. Samples containing a FLT3 ITD (GL-1, Case 1, and Case 2) have a band with decreased mobility compared to the wild-type FLT3 gene (500 bp in size), which is seen in 17-71, CLGL-90, a dog without ALL, and a representative dog with ALL without the FLT3 ITD.

produced when examining DNA isolated from a healthy dog and five dogs diagnosed with ALL (Figure 1, lanes 5, 6 and data not shown), and this was confirmed by DNA sequencing in each case. In contrast, FLT3 ITDs of differing sizes were found in two other dogs diagnosed with ALL (Figure 1, lanes 8, 9). In total, FLT3 ITDs were found in $2 / 7$ (28.5\%) dogs diagnosed with ALL. In contrast to the GL-1 ITD, which produced only one $>500$ bp amplicon, the wild-type FLT3 allele was also seen in these canine ALL blood samples, either indicating heterozygosity or contamination with nonleukemic cells. Similar to the cell line analysis, no point mutations were found in exons $14 / 15$ or exon 20 in any of the seven cases.

The predicted amino acid sequence of the ITDs is shown in Figure 2, based on our DNA sequence data. The GL-1 ITD is an in-frame 21 bp duplication, while the clinical cases contain in-frame $47 \mathrm{bp}$ and $87 \mathrm{bp}$ duplications, respectively. All maintain the same open reading frame as the original FLT3 sequence. Intervening bases between the repeats that maintain the reading frame in Cases 1 and 2 cause the insertion of an extra one to two bases between duplications (Figure 2). Case 2 has an additional point mutation resulting in a $\mathrm{V}$ to $\mathrm{E}$ change in the duplicated repeat (Figure 2).

QFRYESQLQMVQVTGSLDNEYFYIDFREYEYDLKWEFPRENLEF

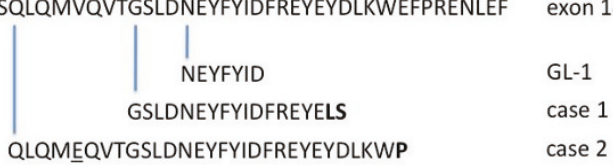

Figure 2 FLT3 ITD mutations in exon 14. The amino acid sequences of the three FLT3 ITD mutations are shown, with the duplicated region shown below the wild-type sequence of exon 14 for each case. The bolded amino acid(s) are not part of the wildtype sequence and exist between the two repeats (not duplicated). The underlined residue in Case 2 is mutated in the duplication only; the other copy is wild-type. Each of the three ITD mutations are inframe. 


\section{Overexpression of FLT3 in samples with a FLT3 ITD mutation}

To begin to define the functional consequences of FLT3 mutations, we compared FLT3 mRNA expression between samples with and without ITDs. Figure 3 shows qRT-PCR results for the three canine lymphoid cell lines, normal canine peripheral blood, and canine ALL cases with and without FLT3 ITDs. GL-1 FLT3 mRNA expression was up-regulated relative to other lymphoid cell lines by more than 30-fold. Likewise, the two clinical ALL cases with a FLT3 ITD mutation had more than 30 -fold increased expression relative to the ALL case without a FLT3 ITD mutation.

\section{Canine FLT3 ITD mutations are associated with lestaurtinib sensitivity}

The FLT3 ITD results in sensitivity to FLT3 inhibition in human cells in vitro. We determined whether the GL-1 cell line, containing the FLT3 ITD, is sensitive to the FLT3 tyrosine kinase inhibitor, lestaurtinib (Figure 4). A dose dependent growth inhibition of the GL-1 cells was clearly evident, with an approximately $40 \%$ growth reduction after being exposed to $10 \mathrm{nM}$ lestaurtinib for 96 hrs. This was similar to the response of MV4-11, a human leukemia cell line with a FLT3 ITD mutation and documented sensitivity to lestaurtinib $[29,30]$. In contrast, the 17-71 cell line was essentially resistant to the growth inhibitory effects of lestaurtinib, while the CLGL90 cell line showed only a modest reduction in growth. The culture conditions required to keep primary canine lymphoma and leukemia cells alive for relevant in vitro studies are not currently known, therefore, the growth inhibitory effect of lestaurtinib on neoplastic cells isolated from the canine ALL patients was not examined.

\section{Canine FLT3 ITD mutation activates the same downstream mediators as in humans}

Finally, in an effort to determine if the downstream effectors of FLT3 inhibition are similar between the canine and human cell lines, we examined the expression and activation of FLT3 and members of the JAK/ STAT and MAP kinase pathways with and without exposure to lestaurtinib (Figure 5). Upon FLT3 phosphorylation and dimerization, both downstream

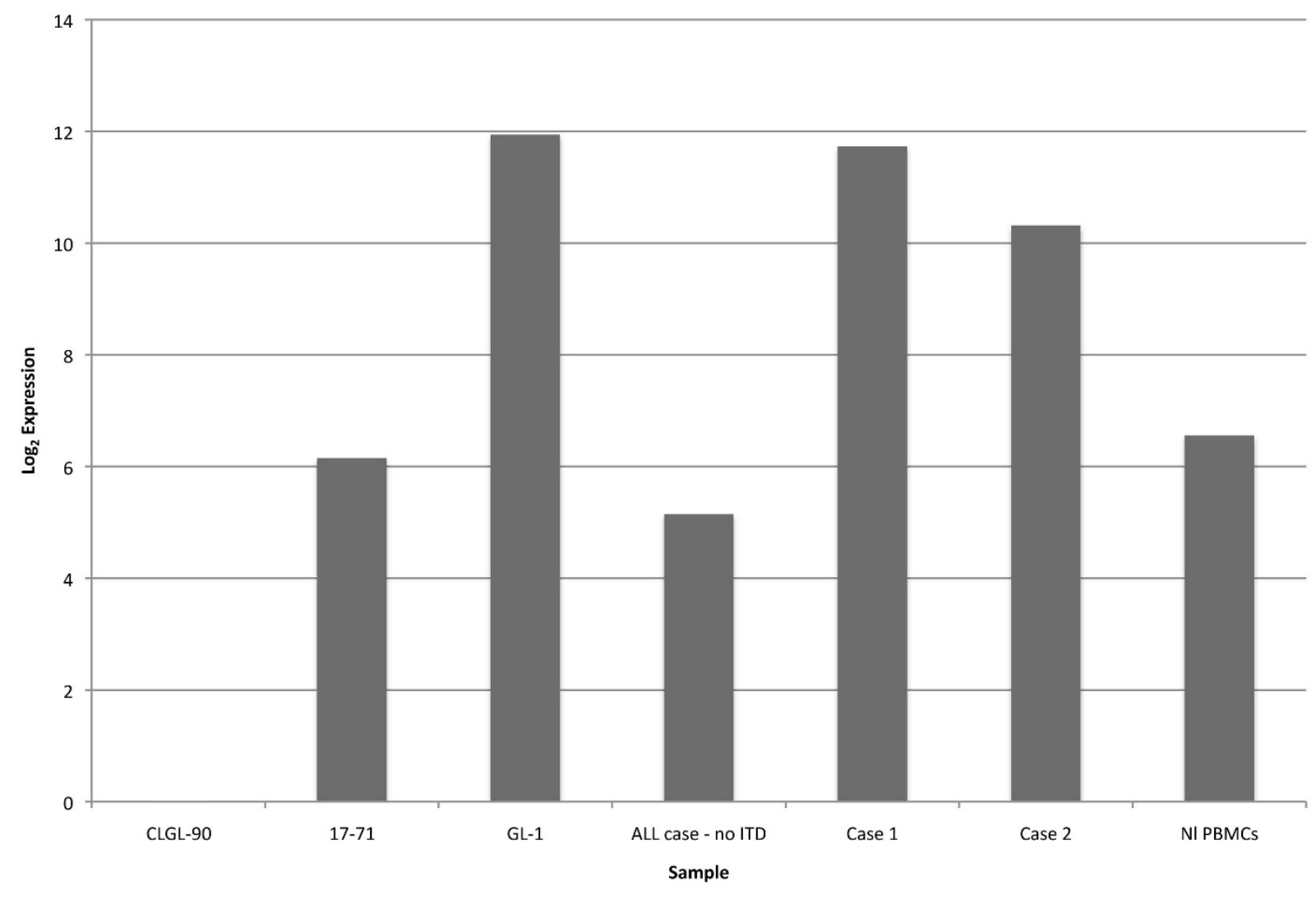

Figure 3 Expression of FLT3 mRNA. Samples were analyzed by quantitative PCR (Q-PCR) of FLT3. Expression levels relative to CLGL-90, which is normalized to zero, are shown in $\log _{2}$ units. 


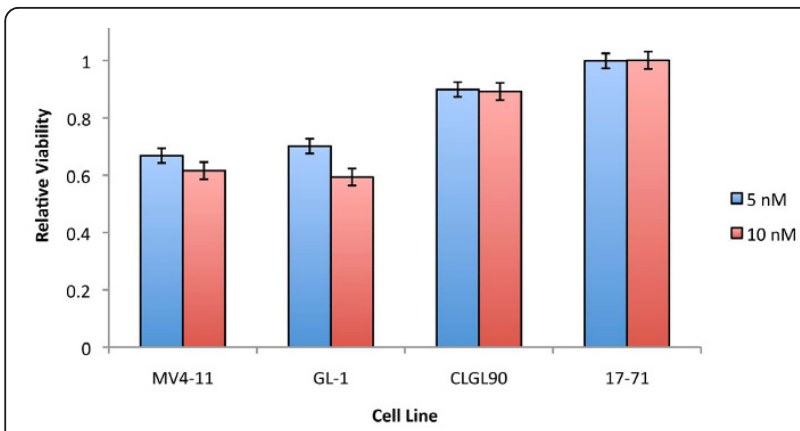

Figure 4 Growth inhibition of FLT3 ITD-containing cell lines by lestaurtinib. Cells were grown in 5 or $10 \mathrm{nM}$ lestaurtinib. Viability of each cell line is shown relative to its growth in media without lestaurtinib. Experiments were done in triplicate, and standard error of the mean is shown.

secondary mediators STAT5 and ERK1/2 are activated via phosphorylation of key residues, which leads to transit into the nucleus and increased transcription of a variety of genes involved in cell survival and differentiation. Furthermore, it has been reported that STAT5 activation is a specific effect of the FLT3 ITD, as opposed to other mechanisms of FLT3 up-regulation [31-33]. The canine cell line 17-71 expresses little to no phospho-STAT and phospho-ERK1/2, therefore, no effect of lestaurtinib on this cell line was seen using this assay. The CLGL-90 cell line, on the other hand, expressed a detectable amount of both STAT and ERK1/2. Growth in lestaurtinib had no effect on the phosphorylation status of these two proteins. In contrast, both the human MV4-11 and canine GL-1 cell lines showed a decrease in the phosphorylation of FLT3 (although the phospho-FLT3 antibody did not detect

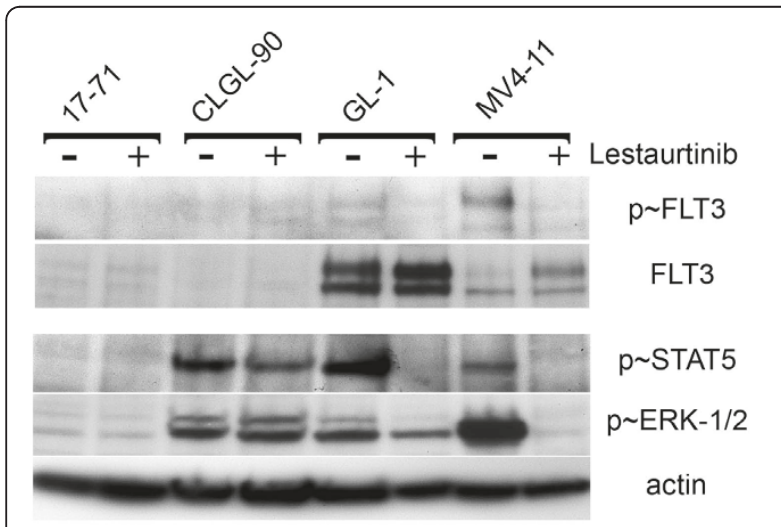

Figure 5 Downstream mediators of FLT3 ITD. Protein levels of FLT3, phospho-FLT3, phospho-STAT5 and phospho-ERK were assayed by Western blotting. Protein was harvested from cell lines that were grown both with and without lestaurtinib. Beta-actin was used as a loading control. canine FLT3 as strongly as human FLT3), STAT5, and ERK1/2 when cultured in the presence of lestaurtinib. In addition, the level of phosphorylated STAT5 was undetectable after exposure to lestaurtinib, while the level of phosphorylated ERK1/2 was decreased in both cell lines.

\section{Discussion}

We have demonstrated that both canine and human leukemias share FLT3 ITD mutations, in agreement with a previous report [19]. In addition, we show that a canine B-cell ALL cell line, GL-1, demonstrates amplification of the FLT3 ITD allele and loss of the wild-type FLT3 allele. Also, this is the first report of FLT3 overexpression in canine ALL clinical samples. Importantly, we also document the conserved functional consequences of the FLT3 ITD mutation. This includes constitutively activated FLT3, leading to increased phosphorylation of downstream mediators, and subsequent sensitivity to the FLT3 inhibitor, lestaurtinib.

Our previous high-resolution aCGH results showing amplification of the FLT3 locus in canine GL-1 cells led us to characterize this gene in more detail. Indeed, FLT3 expression in the GL-1 line is massively upregulated, and the GL-1 cell line contains the FLT3 ITD while lacking wild-type FLT3 (Figure 1). In human AML, copy-neutral loss of wild-type FLT3, also referred to as acquired segmental uniparental disomy (aUPD), is associated with high-risk disease [34]. In a previous survey of canine leukemias, a heterozygous FLT3 ITD was found in 3/36 ( 8.3\%) dogs diagnosed with ALL [19]. Similar to our results, $\mathrm{LOH}$ of dog chromosome $25 \mathrm{q}$ was not seen in this small number of clinical leukemia samples, therefore, loss of wild-type FLT3 is not common in clinical specimens. Although the GL-1 cell line does have $25 \mathrm{q} \mathrm{LOH}$, the normal karyotype reported when this line was originally published cannot distinguish whether loss of the wild-type allele and/or amplification of the FLT3 ITD was present initially or developed with continued in vitro propagation. Regardless, the resulting genotype leads to extensive up-regulation of FLT3 in the GL-1 cell line.

Our results differ from human leukemia in that we observed the FLT3 ITD mutation not infrequently in ALL (2/7 samples), whereas in humans, the FLT3 ITD mutation is only rarely seen in ALL ( $\sim 1 \%$ of ALLs) and is much more common in AML (25\% of adult cases; $15 \%$ of pediatric cases) $[1,2,13-15]$. AML is exceedingly rare in dogs, while ALL is much more common. In canine patients, both diseases are characterized by an extremely aggressive biology with overall short survival times (weeks) when treated with standard multi-agent chemotherapy. Although FLT3 ITDs are uncommon in human ALL, FLT3 overexpression has been implicated 
in the pathogenesis of infant and childhood ALL [16]. Our results showing that FLT3 mutations lead to overexpression and/or activation of FLT3 in both the GL-1 cell line and clinical canine ALL cases is similar to findings examining human ALL cell lines and infant/childhood ALL, although the mechanism of activation more resembles that in human AML (i.e. ITD mutation).

In conjunction with others reports, our results show that, similar to human AML, canine ALL samples also contain differing lengths of ITDs. Also, the canine ITDs maintain the reading frame of the FLT3 protein. These similarities suggest that the mechanism of mutation is conserved across species. Data from human patients suggest that a longer ITD mutation is associated with lower CR rates and worse survivals $[35,36]$. Confirmation in dogs awaits larger numbers and improved treatments to increase overall survival times to a point where cross-species comparisons are possible.

FLT3 plays an important developmental role and is overexpressed in most patients with AML, therefore, it is an attractive target for the development of selective small molecule inhibitors. Lestaurtinib, a FLT3 inhibitor, selectively kills human ALL cell lines and primary childhood ALL cells that express high levels of FLT3. It is also more toxic to AML cell lines with a FLT3 ITD than those without it $[29,30]$. Our findings demonstrate that the canine GL-1 cell line, which exhibits high-level FLT3 expression and the FLT3 ITD mutation, is also sensitive to low concentrations of lestaurtinib. This result mirrors the effects of lestaurtinib on the human leukemia cell line MV4-11, which, like GL-1, contains a FLT3 ITD mutation with high expression levels $[29,30]$. In addition, we confirmed that the inhibition of proliferation of the GL-1 cell line by lestaurtinib is most likely mediated via decreased levels of the STAT5 and ERK1/2 phosphoproteins, all of which reinforces the underlying conservation between dysregulated pathways in humans and canine leukemia, even across diseases (AML and ALL, respectively).

\section{Conclusions}

In summary, we present data that shows ALL/FLT3 biology is conserved across human and canine species. Canine ALL patients, in addition to the canine B-cell leukemia cell line, GL-1, contain FLT3 mutations that lead to FLT3 up-regulation and subsequent activation of members of the JAK/STAT and MAP kinase pathways. In particular, the GL-1 cell line, which has massively up-regulated FLT3 expression as well as a typical FLT3 ITD mutation, will serve as a sensitive tool to test FLT3 selective inhibitors. Thus, this data will lay the groundwork for future studies of leukemogenesis, supporting the notion that canine ALL can be viewed as a relevant large animal model for human FLT3 ITD-positive leukemias and is useful for the development of novel therapeutics and/or treatment strategies for both dogs and humans.

\section{Acknowledgements}

This work was supported by a North Carolina State University Faculty Research and Professional Development Fund Grant (SES) and a developmental grant from the University Cancer Research Fund administered by the Lineberger Comprehensive Cancer Center (SES, MB, $\mathrm{KLR})$.

\section{Author details}

${ }^{1}$ Department of Clinical Sciences, College of Veterinary Medicine, North Carolina State University, Raleigh, NC, USA. ${ }^{2}$ Center for Comparative Medicine and Translational Research, North Carolina State University, Raleigh, NC, USA. ${ }^{3}$ Lineberger Comprehensive Cancer Center, Chapel Hill, NC, USA.

${ }^{4}$ Department of Molecular Biomedical Sciences, College of Veterinary Medicine, North Carolina State University, Raleigh, NC, USA. ${ }^{5}$ Division of Hematology/Oncology, University of North Carolina at Chapel Hill; NC, USA.

\section{Authors' contributions}

SES contributed to the conception and design of the study, collected the clinical samples, analyzed data and wrote the manuscript. GWS performed the FLT3 PCR and mutation analysis, the FLT3 western blots, the cell culture experiments, and analyzed data. ELS performed the FLT3 expression experiment and analyzed data. RT and MB analyzed data and edited the manuscript. KLR contributed to the conception and design of the study, analyzed data, and revised the manuscript. All authors read and approved the final manuscript

\section{Competing interests}

KLR was on the speakers bureau for Cephalon Oncology in 2008-2009.

Received: 2 August 2010 Accepted: 27 January 2011

Published: 27 January 2011

\section{References}

1. Gilliland DG, Griffin JD: The roles of FLT3 in hematopoiesis and leukemia. Blood 2002, 100:1532-1542.

2. Small D: FLT3 mutations: biology and treatment. Hematology Am SoC Hematol Educ Program 2006, 178-184.

3. Abu-Duhier FM, Goodeve AC, Wilson GA, Care RS, Peake IR, Reilly JT: Identification of novel FLT-3 Asp835 mutations in adult acute myeloid leukaemia. Br J Haematol 2001, 113:983-988.

4. Drexler HG: Expression of FLT3 receptor and response to FLT3 ligand by leukemic cells. Leukemia 1996, 10:588-599.

5. Meierhoff G, Dehmel U, Gruss HJ, Rosnet O, Birnbaum D, Quentmeier H, Dirks W, Drexler HG: Expression of FLT3 receptor and FLT3-ligand in human leukemia-lymphoma cell lines. Leukemia 1995, 9:1368-1372.

6. Nakao M, Yokota S, Iwai T, Kaneko H, Horiike S, Kashima K, Sonoda Y, Fujimoto T, Misawa S: Internal tandem duplication of the flt3 gene found in acute myeloid leukemia. Leukemia 1996, 10:1911-1918.

7. Yamamoto Y, Kiyoi H, Nakano Y, Suzuki R, Kodera Y, Miyawaki S, Asou N, Kuriyama K, Yagasaki F, Shimazaki C, et al: Activating mutation of D835 within the activation loop of FLT3 in human hematologic malignancies. Blood 2001, 97:2434-2439.

8. Grundler R, Miething C, Thiede C, Peschel C, Duyster J: FLT3-ITD and tyrosine kinase domain mutants induce 2 distinct phenotypes in a murine bone marrow transplantation model. Blood 2005, 105:4792-4799.

9. Li L, Piloto O, Nguyen HB, Greenberg K, Takamiya K, Racke F, Huso D, Small D: Knock-in of an internal tandem duplication mutation into murine FLT3 confers myeloproliferative disease in a mouse model. Blood 2008, 111:3849-3858.

10. Birg F, Courcoul M, Rosnet O, Bardin F, Pebusque MJ, Marchetto S, Tabilio A, Mannoni P, Birnbaum D: Expression of the FMS/KIT-like gene FLT3 in human acute leukemias of the myeloid and lymphoid lineages. Blood 1992, 80:2584-2593.

11. Carow CE, Levenstein M, Kaufmann SH, Chen J, Amin S, Rockwell P, Witte L Borowitz MJ, Civin Cl, Small D: Expression of the hematopoietic growth 
factor receptor FLT3 (STK-1/Flk2) in human leukemias. Blood 1996, 87:1089-1096

12. Shih $L Y$, Lin TL, Wang PN, Wu JH, Dunn P, Kuo MC, Huang CF: Internal tandem duplication of fms-like tyrosine kinase 3 is associated with poor outcome in patients with myelodysplastic syndrome. Cancer 2004, 101:989-998.

13. Kiyoi H, Naoe T, Nakano Y, Yokota S, Minami S, Miyawaki S, Asou N, Kuriyama K, Jinnai I, Shimazaki C, et al: Prognostic implication of FLT3 and $\mathrm{N}$-RAS gene mutations in acute myeloid leukemia. Blood 1999, 93:3074-3080.

14. Kottaridis PD, Gale RE, Frew ME, Harrison G, Langabeer SE, Belton AA, Walker H, Wheatley K, Bowen DT, Burnett AK, et al: The presence of a FLT3 internal tandem duplication in patients with acute myeloid leukemia (AML) adds important prognostic information to cytogenetic risk group and response to the first cycle of chemotherapy: analysis of 854 patients from the United Kingdom Medical Research Council AML 10 and 12 trials. Blood 2001, 98:1752-1759.

15. Meshinchi S, Stirewalt DL, Alonzo TA, Zhang Q, Sweetser DA, Woods WG, Bernstein ID, Arceci RJ, Radich JP: Activating mutations of RTK/ras signal transduction pathway in pediatric acute myeloid leukemia. Blood 2003, 102:1474-1479.

16. Brown P, Levis M, Shurtleff S, Campana D, Downing J, Small D: FLT3 inhibition selectively kills childhood acute lymphoblastic leukemia cells with high levels of FLT3 expression. Blood 2005, 105:812-820.

17. Khanna C, Lindblad-Toh K, Vail D, London C, Bergman P, Barber L, Breen M, Kitchell B, McNeil E, Modiano JF, et al: The dog as a cancer model. Nat Biotechnol 2006, 24:1065-1066.

18. Vail DM, MacEwen EG: Spontaneously occurring tumors of companion animals as models for human cancer. Cancer Invest 2000, 18:781-792.

19. Usher SG, Radford AD, Villiers EJ, Blackwood L: RAS, FLT3, and C-KIT mutations in immunophenotyped canine leukemias. Exp Hematol 2009, 37:65-77.

20. Breen M, Modiano JF: Evolutionarily conserved cytogenetic changes in hematological malignancies of dogs and humans-man and his best friend share more than companionship. Chromosome Res 2008, 16:145-154.

21. Lindblad-Toh $K$, Wade CM, Mikkelsen TS, Karlsson EK, Jaffe DB, Kamal M, Clamp M, Chang JL, Kulbokas EJ, Zody MC, et al: Genome sequence, comparative analysis and haplotype structure of the domestic dog. Nature 2005, 438:803-819.

22. Nakaichi M, Taura Y, Kanki M, Mamba K, Momoi Y, Tsujimoto H, Nakama S: Establishment and characterization of a new canine B-cell leukemia cell line. J Vet Med Sci 1996, 58:469-471.

23. Steplewski Z, Jeglum KA, Rosales C, Weintraub N: Canine lymphomaassociated antigens defined by murine monoclonal antibodies. Cancer Immunol Immunother 1987, 24:197-201.

24. Suter SE, Chein MB, von Messling V, Yip B, Cattaneo R, Vernau W, Madewell $B R$, London CA: In vitro canine distemper virus infection of canine lymphoid cells: a prelude to oncolytic therapy for lymphoma. Clin Cancer Res 2005, 11:1579-1587.

25. Quentmeier H, Reinhardt J, Zaborski M, Drexler HG: FLT3 mutations in acute myeloid leukemia cell lines. Leukemia 2003, 17:120-124.

26. Wunderli PS, Felsburg PJ: An improved method for the isolation of enriched canine peripheral blood mononuclear cell and peripheral blood lymphocyte preparations. Vet Immunol Immunopathol 1989, 20:335-344.

27. Etschmann B, Wilcken B, Stoevesand K, von der Schulenburg A, SternerKock A: Selection of reference genes for quantitative real-time PCR analysis in canine mammary tumors using the GeNorm algorithm. Vet Pathol 2006, 43:934-942.

28. Pfaffl MW: A new mathematical model for relative quantification in realtime RT-PCR. Nucleic Acids Res 2001, 29:e45.

29. Spiekermann K, Dirschinger RJ, Schwab R, Bagrintseva K, Faber F, Buske C, Schnittger S, Kelly LM, Gilliland DG, Hiddemann W: The protein tyrosine kinase inhibitor SU5614 inhibits FLT3 and induces growth arrest and apoptosis in AML-derived cell lines expressing a constitutively activated FLT3. Blood 2003, 101:1494-1504.

30. Levis M, Allebach J, Tse KF, Zheng R, Baldwin BR, Smith BD, Jones-Bolin S, Ruggeri B, Dionne C, Small D: A FLT3-targeted tyrosine kinase inhibitor is cytotoxic to leukemia cells in vitro and in vivo. Blood 2002, 99:3885-3891.
31. Choudhary C, Muller-Tidow C, Berdel WE, Serve H: Signal transduction of oncogenic Flt3. Int J Hematol 2005, 82:93-99.

32. Choudhary C, Schwable J, Brandts C, Tickenbrock L, Sargin B, Kindler T, Fischer T, Berdel WE, Muller-Tidow C, Serve H: AML-associated Flt3 kinase domain mutations show signal transduction differences compared with Flt3 ITD mutations. Blood 2005, 106:265-273.

33. Obermann EC, Arber C, Jotterand M, Tichelli A, Hirschmann P, Tzankov A: Expression of pSTAT5 predicts FLT3 internal tandem duplications in acute myeloid leukemia. Ann Hematol 2010, 89:663-669.

34. Dunbar AJ, Gondek LP, O'Keefe CL, Makishima H, Rataul MS, Szpurka H, Sekeres MA, Wang XF, McDevitt MA, Maciejewski JP: $250 \mathrm{~K}$ single nucleotide polymorphism array karyotyping identifies acquired uniparental disomy and homozygous mutations, including novel missense substitutions of c-Cbl, in myeloid malignancies. Cancer Res 2008, 68:10349-10357.

35. Meshinchi S, Stirewalt DL, Alonzo TA, Boggon TJ, Gerbing RB, Rocnik JL, Lange BJ, Gilliland DG, Radich JP: Structural and numerical variation of FLT3/ITD in pediatric AML. Blood 2008, 111:4930-4933.

36. Stirewalt DL, Kopecky KJ, Meshinchi S, Engel JH, Pogosova-Agadjanyan EL, Linsley J, Slovak ML, Willman CL, Radich JP: Size of FLT3 internal tandem duplication has prognostic significance in patients with acute myeloid leukemia. Blood 2006, 107:3724-3726.

\section{Pre-publication history}

The pre-publication history for this paper can be accessed here: http://www.biomedcentral.com/1471-2407/11/38/prepub

doi:10.1186/1471-2407-11-38

Cite this article as: Suter et al:: FLT3 mutations in canine acute lymphocytic leukemia. BMC Cancer 2011 11:38.

\section{Submit your next manuscript to BioMed Central and take full advantage of:}

- Convenient online submission

- Thorough peer review

- No space constraints or color figure charges

- Immediate publication on acceptance

- Inclusion in PubMed, CAS, Scopus and Google Scholar

- Research which is freely available for redistribution

Submit your manuscript at www.biomedcentral.com/submit
C Biomed Central 